\title{
Employee engagement and Emotional Exhaustion of Fly-In-Fly-Out Workers: A Diary Study
}

\author{
Simon L. Albrecht and Jeromy Anglim \\ School of Psychology, Deakin University, Victoria, Australia ${ }^{1}$
}

\begin{abstract}
.
Objective: Although Fly-in-Fly-Out (FIFO) work practices are widely used, little is known about their impact on the motivation and wellbeing of FIFO workers across the course of their work cycles. Drawing from the Job Demands-Resources model, we aimed to test for the withinperson effects of time of work cycle, job demands, and job resources on emotional exhaustion and employee engagement at three day-intervals. Method: Fifty-two FIFO workers filled out three or more on-line diary surveys after every three days of their on-site work roster. The survey consisted of items drawn from previously validated scales. Bayesian hierarchical modeling of the day-level data was conducted. Results: Workers, on average, showed a decline in engagement and supervisor support, and an increase in emotional demand over the course of the work cycle. The results of the hierarchical modeling showed that day-level autonomy predicted day-level engagement and that day-level workload and emotional demands predicted emotional exhaustion. Conclusions: The findings highlight the importance of managing FIFO employees' day-to-day experiences of job demands and job resources because of their influence on employee engagement and emotional exhaustion. To best protect FIFO worker day-level wellbeing, employing organisations should ensure optimal levels of job autonomy, workload, and emotional demands. Practical implications, study limitations and areas for future research are outlined.
\end{abstract}

Keywords: Work engagement; Job demands; Job resources; Emotional exhaustion; Diary study.

\section{Key Points}

\section{What is already known about this topic}

- Work conditions are known to influence the motivation and wellbeing of workers across a variety of contexts.

- Concerns have been raised about the impact of FIFO work practices on the health and wellbeing of individual FIFO workers.

- The Job Demands-Resources model provides a well-validated framework for understanding employee motivation and wellbeing.

\section{What this topic adds}

- The present research is the first to examine within-person variation in job demands, job resources, engagement, and emotional exhaustion across the FIFO work cycle.

\footnotetext{
${ }^{1}$ Citation Information: Albrecht, S. L., \& Anglim, J. (2018). Employee engagement and Emotional Exhaustion of Fly-In-Fly-Out Workers: A Diary Study. Australian Journal of Psychology. 70, 66-75. http://dx.doi.org/10.1111/ajpy.12155
}

This is not the copy of record. Copyright is owned by the publisher. See doi link above for copy of record. Correspondence: Simon L. Albrecht, School of Psychology, Deakin University, Locked Bag 20000, Geelong 3220, Australia. Email: simon.albrecht@ deakin.edu.au 
- The present research suggests that to best protect FIFO worker wellbeing, employing organisations should ensure optimal levels of job autonomy, workload, and emotional demands.

- The present research is the first to employ Bayesian hierarchical methods to model employee diary data.

Fly-in-fly-out (FIFO) work arrangements are common to large oil, gas, mining and construction projects around the world (Muller, Carter \& Williamson, 2008; Storey, 2010). In a typical FIFO working scenario, a worker who resides in a large city or town is flown to a remote location to work long shifts (e.g., 12 hours each day) on a two, three or four week roster, before flying home at the conclusion of their roster to have a one or two week break (Joyce, Tomlin, Somerford, \& Weeramanthri, 2013). Despite the prevalence of FIFO work practices, concerns have been expressed about their impact on the health and wellbeing of individual FIFO workers. For example, recent Australian government reports have noted that depression, anxiety and suicide are of serious concern and that more research on the mental health of FIFO workers is needed (Western Australian Government Education and Health Standing Committee, 2015; Australian Government House of Representatives Standing Committee on Regional Australia, 2013). Although the Western Australian Government report, for example, acknowledged that definitive prevalence data on mental illness and suicide rates among FIFO workers is "difficult to find" (p. i), it concluded there is sufficient evidence of moderately serious mental health difficulties in approximately 30 per cent of FIFO workers. Vojnovic and Bahn (2015) similarly reported that $36 \%$ of the FIFO workers they surveyed "experienced depression, anxiety and/or stress symptoms above the clinical cut-off levels" (p. 207).

Although there is a growing body of qualitative research aimed at understanding the impact of FIFO work conditions on FIFO worker wellbeing (e.g., Pini \& Mayes, 2012; Torkington, Larkins, \& Gupta, 2011), there is only a limited amount of quantitative research (e.g., Joyce et al., 2012; Muller, Carter \& Williamson, 2008; Vojnovic \& Bahn, 2015). The limited amount of quantitative research has been largely descriptive rather than inferential, and provides only limited insight into the factors that influence or cause FIFO worker wellbeing, burnout and distress. Given an extensive amount of quantitative research conducted in other work domains has confirmed that psychosocial factors such as job autonomy, supervisor support, workload and emotional demands influence employee wellbeing and performance (e.g., Darr \& Johns, 2008; Hausser, Mojzisch, Niesel \& Schulz-Hardt, 2010; Stansfeld, \& Candy, 2006; Viswesvaran, Sanchez \& Fisher, 1999), it is important to establish if such research findings generalize to the FIFO context. Beyondblue's (2014) submission to the Western Australian Government report acknowledged that additional "research is needed to identify the .... factors that put workers at risk for mental health issues, as well as those factors that enable workers to maintain their mental wellbeing" (p. 2). The present research aims to redress the lack of quantitative research focused on identifying how job characteristics influence FIFO worker emotional wellbeing and engagement.

\section{FIFO Work and Job Demands-Resources Theory}

Although research on FIFO work practices has generally proceeded along a-theoretical lines, several theories can sensibly be invoked to understand the causes of employee engagement, burnout and performance in FIFO working contexts. Such theories include the Job Demands-Resources theory (JD-R, Bakker \& Demerouti, 2014). The JD-R model, in particular, 
has underpinned much recent research examining the causes and consequences of "employee wellbeing (e.g., burnout, health, motivation, work engagement) and job performance" (Bakker \& Demerouti, 2014; p. 8). It is noteworthy that a number of researchers have explicitly conceptualized employee engagement as a form of wellbeing (e.g., Albrecht, 2012; Bakker \& Oerlemans, 2011; Schaufeli et al., 2008). Schaufeli et al., for example, argued that the concept of work engagement "emerged from burnout research in an attempt to cover the entire spectrum running from employee unwell- being (burnout) to employee well- being" (p. 176). The JD-R has advantages over alternative theoretical frameworks in that it can be applied and tailored to any specific occupation under consideration (Bakker \& Demerouti, 2014).

The JD-R, as originally proposed (Demerouti, Bakker, Nachreiner, \& Schaufeli, 2001), describes how job resources and job demands trigger two independent psychological processes: a motivational process and a health impairment process. With respect to the motivational process, meta-analytic evidence has shown that job resources such as autonomy, task variety, feedback, training and development, participation in decision-making, coworker support, and supervisor support are positively associated with employee engagement across a range of working contexts (e.g., Crawford, Rich, \& LePine, 2010; Halbesleben, 2010). Organisational support (Eisenberger et al., 1986), a general belief that an employee's organisation values their contribution and cares about their wellbeing (Rhoades \& Eisenberger, 2002), has also been shown to influence engagement (Saks, 2006; Tetrick \& Haimann, 2014). Engagement, in turn, has been shown to be associated with positive attitudinal, behavioral and performance outcomes such as task performance, contextual performance, and safety outcomes (e.g., Christian, Gaza \& Slaughter, 2011; Nahrgang, Morgeson \& Hoffman, 2011). With respect to the JD-R's health impairment process, meta-analytic evidence has also shown that job demands such as work overload, role conflict, role ambiguity, and emotional demands adversely impact employee health, wellbeing and performance (e.g., Alarcon, 2011; Nahrgang et al., 2011).

Although propositions with respect to FIFO worker adjustment and wellbeing loosely based on the JD-R have been proposed (Vojnovic et al., 2014), limited JD-R based quantitative research has been published that helps explain the impact of FIFO worker arrangements on FIFO worker engagement, wellbeing and performance. There is, however, qualitative research that suggests some job demands and job resources that are relevant in the FIFO work context. Workload and emotional demands, for example, have been identified as significant stressors in the mining context (Gallegos, 2006; Gent, 2004; Iverson \& Maguire, 1999; Peetz, Murray \& Muurlink 2012; Rothmann \& Joubert, 2007). A lack of privacy in shared and temporary accommodation, and social conformity pressures have been recognized as potential sources of stress in FIFO working contexts (Barclay, Harris, Everingham, Kirsch, Arend, Shi \& Kim, 2013; Pini \& Mayes, 2012). Organisational support in the form of comfortable accommodation, healthy on-site catering, and reliable and efficient internet and telecommunications infrastructure has also been identified as having an important impact on FIFO worker wellbeing (Torkington, Larkins \& Gupta, 2011).

\subsection{Engagement and Burnout}

Work engagement and burnout have traditionally been treated as relatively stable, persistent and enduring psychological states (e.g., Schaufeli et al., 2006). However, it is increasingly being acknowledged that employees show meaningful variation in engagement and burnout over short periods of time. Diary studies have shown that 30 to 70 percent of the variance in engagement and burnout is attributable to within-person variation (Bakker \& Bal, 2010; Mäkikangas, Kinnunen, Rantanen, Mauno, Tolvanen \& Bakker, 2014; Tims, Bakker, \& 
Derks, 2014). To understand and effectively manage FIFO employee wellbeing, it therefore becomes important to model how individual worker experiences change over time (Kuppens, Van Mechelen, Nezlek, Dossche, \& Timmermans, 2007).

Diary studies have shown that job resources such as job autonomy, social support, supervisor coaching, and colleague support predict day-level engagement (Bakker \& Bal, 2010; Breevaart, Bakker \& Demerouti, 2014; Xanthopoulou, Bakker, Demerouti, \& Schaufeli 2009). Researchers have also shown day-level job demands predict day-level emotional exhaustion (e.g., Simbula, 2010, van Gelderen, Bakker, Konijn \& Binneweiss, 2014). As previously noted, no studies, as yet, have examined the potential influence of day-level job resources and job demands on engagement and emotional exhaustion within the FIFO working context.

\subsection{The Current Study}

The aim of the current study was to test a model of how day-to-day experiences of job demands and job resources predict day-to-day wellbeing across the FIFO work cycle. To achieve the aims we conducted a diary study in which FIFO workers rated their job resources, job demands, engagement, and emotional exhaustion after every three days of their on-site work cycle. The hypothesized within-person relationships are summarised in Figure 1.

Hypothesis 1: Variation in job resources (autonomy, supervisor support, cow orker support, and organisational support) will be positively associated with variation in FIFO worker work engagement (measured at three day-intervals).

Hypothesis 2: Variation in job demands (workload and emotional demands) will be positively associated with variation in FIFO worker emotional exhaustion (measured at three day-intervals).

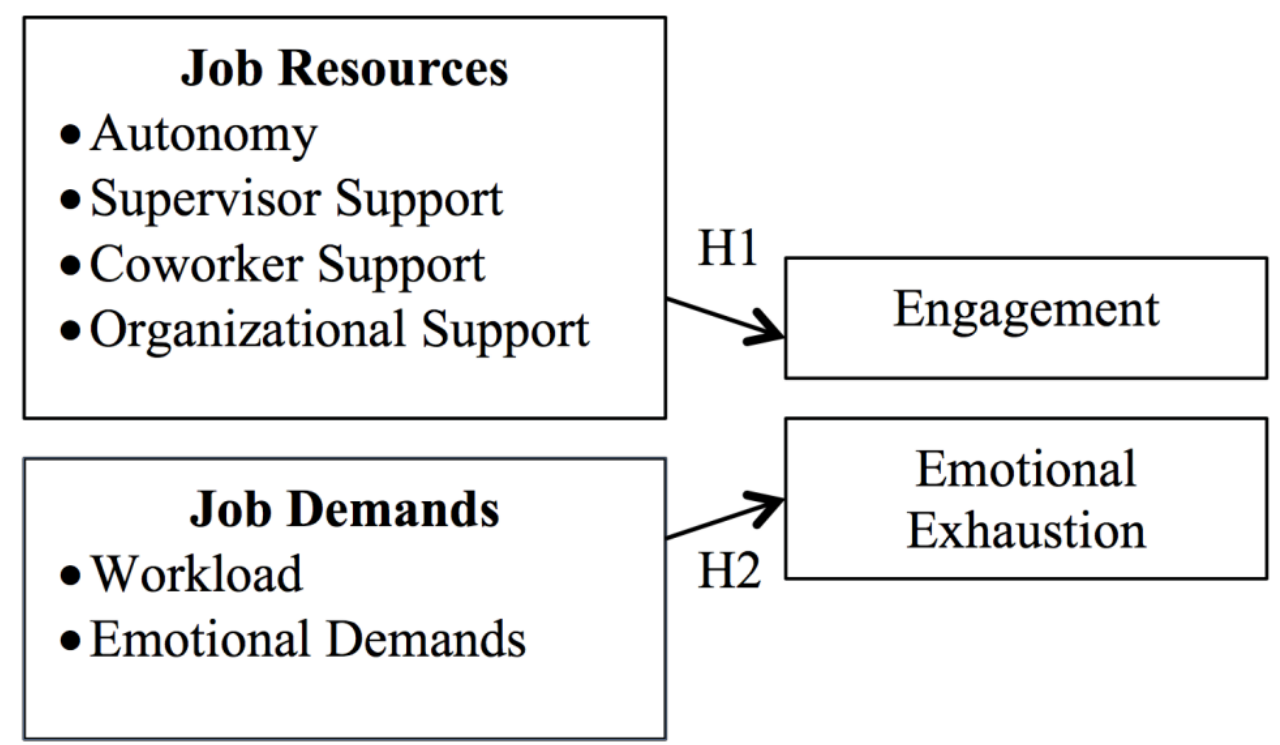

Figure 1. Research model. 


\section{Method}

\subsection{Participants and Procedure}

Participants were recruited from a large multi-national construction company with extensive experience using FIFO work practices. FIFO employees from four separate construction projects were invited to complete an on-line diary survey after every three days of their on-site FIFO work cycle. The three-day time lag provided a sufficiently short period of time to capture within-person variation. An invitation to participate in the research was emailed to all FIFO employees via the host organisation's intranet. The email outlined the aims of the research and conveyed senior management's support for the research project. Those agreeing to participate had the option of signing-up to receive a pack of hard-copy paper surveys or receive online surveys accessible via a URL or Quick Recognition (QR) Code from their smart phone, tablet or computer. All participants opted for online participation and all agreed to receive text message prompts from research assistants to remind them to fill out their online diary surveys after every three days of their on-site work roster.

Of the approximate 500 potential respondents, 79 FIFO workers agreed to participate and completed at least one diary survey. Fifty-two FIFO workers completed three or more diary surveys, yielding a total of 231 useable observations for within-person analyses. The voluntary nature of the participation, concerns about committing to complete a series of surveys, and the completion or decommissioning of some projects throughout the research cycle may have contributed to the less than expected participation and attrition rates. Nevertheless, the final number of participants clearly exceeded Maas and Hox's (2005) criterion of 30 or more cases at the highest level of multilevel analyses.

Participants occupied a range of roles (e.g. operator, process technician, administrative support, manager, senior manager), and worked rosters of two-weeks on and one-week off (35\%), three weeks on and one week off (55\%), four weeks on and one week off (7.5\%), or 26 days on and 9 days off (2.5\%). Longer work cycles allowed for more measurement occasions with mean number of measurement occasions of 3.71 for two-week rosters, 3.55 for 3 weeks and 7.0 for four weeks on. Consistent with the host organisation's FIFO demographics, the majority of the participants were male (62.7\%). Tenure at the organization ranged from 0.11 to 10.00 years $(\mathrm{M}=$ 2.62, SD = 2.34). The length of time that an employee had been working FIFO at the organisation ranged from 0.11 to 4.00 years $(\mathrm{M}=1.42, \mathrm{SD}=1.08)$.

\subsection{Measures}

Given that measures used in diary studies typically consist of a reduced number of items derived from previously validated between-person scales (e.g., Ouweneel, Le Blanc, Schaufeli \& van Wijhe, 2012; Simbula, 2010; Tims, Bakker \& Derks, 2014; Xanthopoulou et al., 2008), two to five items for each construct were selected on the basis of their previously published loadings and content validity. For all scales participants were asked to rate their work experience "over the past three days at work".

The items measuring job resources and workload were measured on a seven-point Likert scale ranging from $1=$ "strongly disagree" to $7=$ "strongly agree". Job autonomy was measured using two items adapted from Spreitzer's (1995) self-determination scale. Supervisor support and coworker support were each measured using two items adapted from Albrecht and Su (2012) and Xanthopoulou, Bakker, Demerouti, and Schaufeli (2007). Organisational support was measured using four items adapted from Eisenberger et al.'s (1986) perceived organisational support scale. 
Workload was measured using two items adapted from Karasek's (1979) Job Content Questionnaire. Emotional demands, emotional exhaustion and engagement were measured with items adapted from previously published scales (Karasek, 1979; Rich, LePine \& Crawford, 2010; Schaufeli, Bakker \& Salanova, 2006; Schaufeli, Leiter, Maslach \& Jackson, 1996; Zapf, Seifert, Schmutte, Mertini \& Holz, 2001), anchored on a scale ranging from $0=$ "never" to $6=$ "almost always". The full set of items, alpha reliabilities, and confirmatory factor analytic evidence in support of the measures are presented in the results section below.

\subsection{Data Analytic Approach}

We used Bayesian hierarchical methods to estimate the proposed within-person relationships (see Figure 1). The Bayesian approach offers a flexible, coherent, and integrated approach to parameter estimation and inference that provides additional sophistication in modeling longitudinal data (see Gelman \& Hill, 2007). The Bayesian approach has several advantages over the traditional multilevel analyses. First, it allows for estimation of covariate person-means and day-level deviations using a latent variable approach. This overcomes the problem of standard group-mean centering whereby the latent group-mean is incorrectly assumed to be measured without error. Second, the Bayesian approach allows within-person error variance to be treated as a quantity that varies over individuals. This specifically allows estimation of the degree to which employees vary not just in their means, but also in their day-today variability (Anglim, Weinberg \& Cummins, 2015). Overall, the proposed model analysis is similar to a standard multilevel modeling in predicting an outcome (e.g., engagement) using a random-intercept and fixed effects for person-mean centered covariates (e.g., job resources and job demands). However, the person-mean centering is done using a latent variable approach, and the error variance is allowed to vary over people.

With respect to testing the model, parameter estimates were obtained using a Bayesian approach and Markov-Chain Monte-Carlo (MCMC) methods using JAGS (Plummer, 2003). To facilitate parameter interpretation, all variables in the multilevel models were $\mathrm{Z}$-score standardized based on the time 1 means and standard deviations (see Table 2). Bayesian methods require the specification of a prior distribution on all parameters. We used uniform priors on all parameters reflecting the range of possible and plausible values. Such uniform priors allow the model likelihood to drive parameter estimation.

\section{Results}

\subsection{Confirmatory Factor Analysis}

Confirmatory factor analysis (CFA) was performed using the lavaan package in $\mathrm{R}$ (Rosseel, 2012) to assess the proposed eight-factor measurement model. To maximize robustness, data from all 79 participants who provided time 1 data were included in the analysis. For factors with only two items, unstandardized loadings were constrained to be equal. Although the initial fit statistics suggested reasonable fit $\left({ }^{2}=276, \mathrm{df}=186, p<.001\right.$, RMSEA=.078, $\mathrm{SRMR}=.067, \mathrm{CFI}=.940$ ), based on an examination of the modification indices, four of the 24 pairs of within-scale item residuals were allowed to correlate. The respecified CFA yielded very

good fit: ${ }^{2}=288, \mathrm{df}=182, \mathrm{RMSEA}=.057, \mathrm{SRMR}=.064, \mathrm{CFI}=.969$. Table 1 shows the standardized loadings for each of the items (average loading $=.86$ ). 
Table 1

Scales, Items, and Factor Loadings

\begin{tabular}{|c|c|c|}
\hline Scale & Items & $\begin{array}{l}\text { Standardized } \\
\text { Loading } \\
\end{array}$ \\
\hline \multirow{2}{*}{ Autonomy } & 1. I had significant control over how I carried out my work & .87 \\
\hline & 2. I could decide on my own how to go about doing my work & .77 \\
\hline \multirow{2}{*}{$\begin{array}{l}\text { Supervisor } \\
\text { support }\end{array}$} & 3. I could count on my Supervisor to help me if I need it & .87 \\
\hline & 4. I felt valued by my Supervisor & .92 \\
\hline \multirow{2}{*}{$\begin{array}{l}\text { Coworker } \\
\text { support }\end{array}$} & 5. I could count on my co-workers to help me if I needed it & .85 \\
\hline & 6. I felt valued by my co-workers & .93 \\
\hline \multirow{4}{*}{$\begin{array}{l}\text { Organ- } \\
\text { izational } \\
\text { support }\end{array}$} & $\begin{array}{l}\text { 7. I felt my organization was genuinely trying to look after its } \\
\text { FIFO employees }\end{array}$ & .97 \\
\hline & $\begin{array}{l}\text { 8. I felt my organization really cares about its FIFO } \\
\text { employees }\end{array}$ & .97 \\
\hline & $\begin{array}{l}\text { 9. I felt my organization provided enough 'on the job' } \\
\text { resources so I could do my job effectively }\end{array}$ & .76 \\
\hline & $\begin{array}{l}\text { 10. I felt my organization provided enough 'on site' resources } \\
\text { (e.g., accommodation, access to telecommunications etc.) to } \\
\text { make FIFO a positive work experience }\end{array}$ & .68 \\
\hline \multirow[b]{2}{*}{ Workload } & 11. My workload was too heavy & .93 \\
\hline & $\begin{array}{l}\text { 12. I did not have enough time to do my work to the best of } \\
\text { my ability }\end{array}$ & .91 \\
\hline \multirow{5}{*}{ Engagement } & 13. I tried really hard to perform well on my job & .56 \\
\hline & 14. I was motivated to do a good job for the organization & .79 \\
\hline & 15. I felt full of energy & .82 \\
\hline & 16. I felt very enthusiastic about my job & .95 \\
\hline & 17. I felt very motivated at work & .96 \\
\hline \multirow{2}{*}{$\begin{array}{l}\text { Emotional } \\
\text { demand }\end{array}$} & $\begin{array}{l}\text { 18. I had to suppress my own unhappy feelings (e.g., } \\
\text { irritation, sadness etc.) }\end{array}$ & .94 \\
\hline & $\begin{array}{l}\text { 19. I had to portray myself as being more positive than I was } \\
\text { actually feeling }\end{array}$ & .93 \\
\hline \multirow{3}{*}{$\begin{array}{l}\text { Emotional } \\
\text { exhaustion }\end{array}$} & 20. I felt emotionally drained from my work & .95 \\
\hline & 21. I felt used up at the end of the work day & .78 \\
\hline & 22. I felt burned out from my work & .85 \\
\hline
\end{tabular}

Note. Standardized factor loadings on designated scale derived from CFA reported in results section.

\subsection{Descriptive Statistics and Correlations}

Table 2 reports the Cronbach's alpha reliabilities, intraclass correlation coefficients and descriptive statistics for the study variables. The Cronbach's alphas, derived from time 1 data (n $=79$ ), ranged between .80 and .93 (mean alpha $=.89$ ). The alphas were relatively stable over the 
first three measurements (mean alpha time $1=.895$, time $2=.899$, time $3=.916$ ). In support of multi-level modeling, the intraclass correlations (ICCs), using data from the 52 participants that provided three or more observations, showed that between $19 \%$ and $40 \%$ of the variance in the measured constructs could be attributed to within-person variation. Table 2 also shows withinperson means, and within-person standard deviations, based on time 1 data.

Table 2

Cronbach's Alpha Reliability, Intraclass Correlations, and Descriptive Statistics for Scales

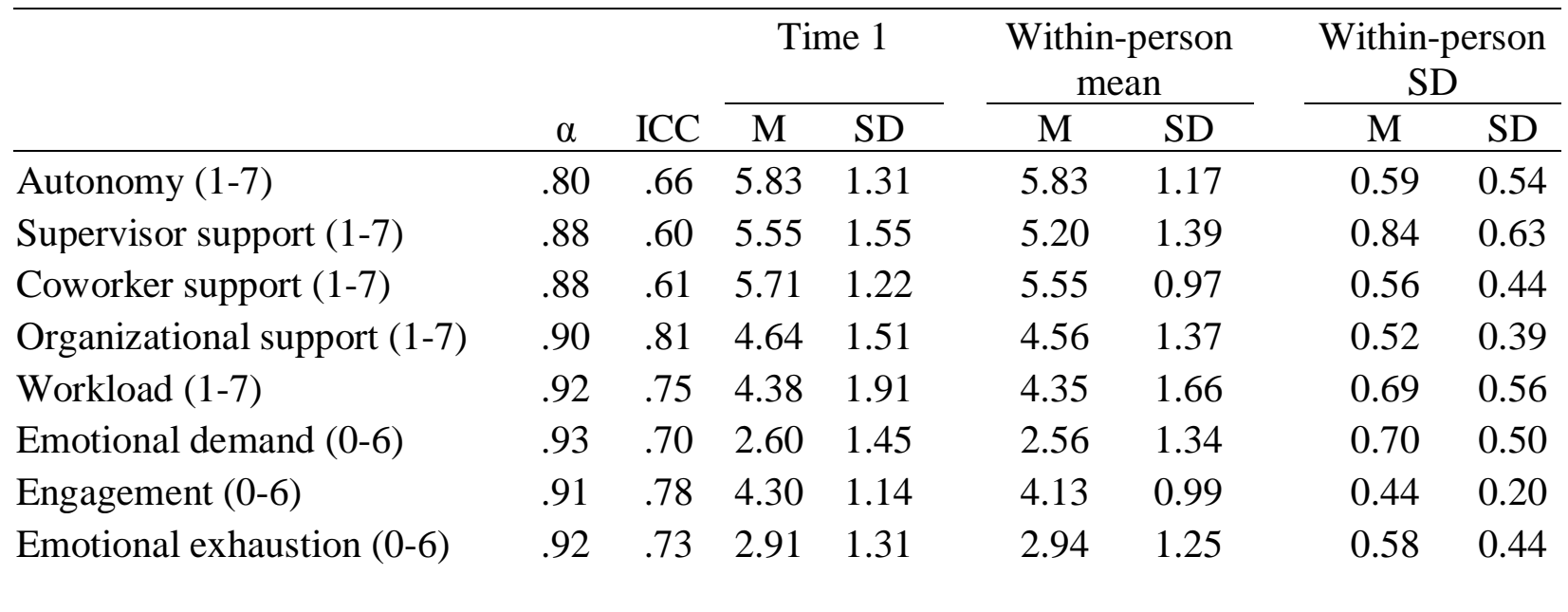

Note. $\alpha$ is Cronbach's alpha based on time 1 diary data. ICC is based on ICC(1) estimate of between person variance as a proportion of total variance.

Table 3 shows the correlations at both within-person and between-person levels. Between-person correlations were calculated using data derived from the mean of each worker across measured time points. Within-person correlations were calculated on data from all time points after first subtracting the person-level mean from each observation. Although the average absolute correlation was larger at the between-person level (mean absolute $r=.48$ ) than at the within-person level (mean absolute $r=.19$ ), the general pattern of correlations was similar. The overall correlation between the 28 between-person and the 28 within-person correlations was $r=$ .89. The within-person correlations provided partial support for the hypothesized relationships (see Figure 1). 
Table 3

Between-Person and Within-Person Correlations

\begin{tabular}{lrrrrrrrr}
\hline & 1 & 2 & 3 & 4 & 5 & 6 & 7 & 8 \\
\hline 1. Autonomy & - & $\mathbf{. 7 1}$ & $\mathbf{. 4 5}$ & $\mathbf{. 6 3}$ & -.22 & $\mathbf{- . 4 6}$ & .16 &.$- \mathbf{4 5}$ \\
2. Supervisor support & $\mathbf{. 4 6}$ & - & $\mathbf{. 5 8}$ & $\mathbf{. 5 8}$ & -.27 & $\mathbf{- . 4 6}$ & $\mathbf{. 3 2}$ & $\mathbf{- . 4 1}$ \\
3. Coworker support & $\mathbf{. 3 7}$ &. $\mathbf{2 6}$ & - & $\mathbf{. 6 7}$ & $\mathbf{- . 3 7}$ & $\mathbf{- . 5 0}$ & $\mathbf{. 5 2}$ & $\mathbf{- . 4 2}$ \\
4. Organizational support & $\mathbf{. 2 5}$ & $\mathbf{. 3 1}$ & $\mathbf{. 5 1}$ & - & $-\mathbf{. 5 5}$ & $\mathbf{- . 7 1}$ & $\mathbf{. 5 0}$ & $\mathbf{- . 6 9}$ \\
5. Workload & -.09 & -.08 & .03 & .00 & - & $\mathbf{. 3 9}$ & -.13 & $\mathbf{. 7 0}$ \\
6. Emotional demand & -.08 & -.21 & -.09 & -.03 & .12 & - &.- .39 & $\mathbf{. 6 6}$ \\
7. Engagement & $\mathbf{. 3 1}$ & $\mathbf{. 2 9}$ & $\mathbf{. 1 5}$ & $\mathbf{. 2 3}$ & $-\mathbf{. 1 3}$ & -.12 & - & $-\mathbf{. 3 5}$ \\
8. Emotional exhaustion & -.05 &.- .14 & -.12 & -.12 & $\mathbf{. 2 2}$ & $\mathbf{. 4 9}$ & -.12 & - \\
\hline
\end{tabular}

Note. Correlations in upper-right are between person correlations $(\mathrm{N}=52)$, and those in the lowerleft are within-person correlations $(\mathrm{N}=231)$. Absolute correlations greater than or equal to 13 (within-person) or .28 (between-person) are significant at .05 (two-tailed) and are bolded.

\section{3. $\quad$ Model Testing}

Bayesian hierarchical models indicated that with respect to effects due to the time of the work-cycle, small but significant time effects were found for supervisor support (-.06, 95\% CI [$.12, .00])$, engagement (-.07, 95\% CI [-.11, .03], and emotional demands (.05, 95\% CI [-.09 .00]). These parameter values indicate that supervisor support and engagement decreased over the work cycle and emotional demands increased. There were no significant quadratic effects of time for any of the scales.

Table 4 presents parameter estimates of the proposed model predicting engagement and emotional exhaustion from job resources and job demands. In the model predicting engagement the only significant within-person predictor was autonomy $(\beta=0.15)$, although organisational support approached significance (partially supporting Hypothesis 1). In the model predicting emotional exhaustion both workload $(\beta=0.16)$ and emotional demand $(\beta=0.45)$ were significant (supporting Hypothesis 2). 
Table 4

Parameter Estimates for Models Predicting Engagement and Emotional Exhaustion

\begin{tabular}{|c|c|c|}
\hline & Engagement & $\begin{array}{l}\text { Emotional } \\
\text { Exhaustion }\end{array}$ \\
\hline Intercept Mean & $-0.02(0.11)$ & $0.04 \quad(0.09)$ \\
\hline \multicolumn{3}{|l|}{ Level 1 (within-person) } \\
\hline Autonomy 1 & $0.15 *(0.06)$ & $-0.02(0.05)$ \\
\hline Supervisor support 2 & $0.08 \quad(0.05)$ & $-0.01 \quad(0.05)$ \\
\hline Coworker support 3 & $-0.02 \quad(0.07)$ & $-0.07 \quad(0.06)$ \\
\hline Organizational support 4 & $0.16 \quad(0.09)$ & $-0.04 \quad(0.07)$ \\
\hline Workload 5 & $-0.08 \quad(0.07)$ & $0.16^{*}(0.07)$ \\
\hline Emotional demand 6 & $-0.05 \quad(0.06)$ & $0.45^{*}(0.07)$ \\
\hline \multicolumn{3}{|l|}{ Variability parameters } \\
\hline Intercept SD & $0.60(0.09)$ & $0.47(0.07)$ \\
\hline Within-person error mean & $0.41(0.03)$ & $0.45(0.05)$ \\
\hline Within-person error SD & $0.07(0.04)$ & $0.24(0.06)$ \\
\hline$-2 * \log$ likelihood & 13.7 & -11.7 \\
\hline
\end{tabular}

Note. Numbers are mean (and standard deviation in parentheses) of posterior density estimates of parameters and are the Bayesian analogue of point estimates and standard errors respectively. $* \mathrm{p}<.05$.

\section{Discussion}

Drawing from JD-R theory (Bakker \& Demerouti, 2014), this is the first diary study aimed at identifying the temporal dynamics of, and the work conditions that impact on, FIFO worker wellbeing. Firstly, our results showed significant within-person variability across the full range of variables measured. Supervisor support and coworker support showed more withinperson variance $(\sim 40 \%)$ than workload, emotional demand, and emotional exhaustion $(\sim 30 \%)$, and engagement and organisational support $(\sim 20 \%)$. These findings potentially have important implications for the FIFO context in that Kuppens, Van Mechelen, Nezlek, Dossche, and Timmermans (2007) found that the more an individual's affective experience fluctuates over time, the more likely they are to experience decreased wellbeing and adjustment. As such, FIFO workers who have more fluctuating experiences of demands, control and supports may therefore be more likely to experience diminished wellbeing and adjustment. Organisations employing FIFO workers may therefore usefully aim to actively manage selection processes, the design of jobs, working relationships, and working conditions so as to minimize the extent to which workers experience large fluctuations or volatility in their on-site psychosocial work experiences. It is noteworthy that the estimates of within-person variation were somewhat smaller than those reported in some previous JD-R diary studies (e.g., Bakker \& Bal, 2010; Mäkikangas et al., 
2014). The three-day time reference may have reduced the variability relative to hourly or daily sampling schedules. In this sense, our estimates of within-person variance may be conservative.

Our analyses also showed that worker experiences of supervisor support and engagement decreased, and emotional demands increased over the work cycle. These modest but meaningful linear effects, again, suggest the importance of monitoring and managing job demands and job resources across the FIFO work cycle. Supervisors, for example, might be usefully be trained to sustain or increase support over the course of the work cycle. No quadratic trends were evidenced for any of the measured variables.

In terms of testing the proposed model, the results showed that within-person autonomy was a significant predictor of within-person employee engagement. This finding is consistent with previous diary research (e.g., Kühnel, Sonnentag \& Bledow, 2012; Xanthopoulou et al., 2009) and supports the generalizability of the JD-R motivational pathway (Bakker \& Demerouti, 2014) to day-level processes in the FIFO context. The results suggest that providing FIFO employees with significant control and discretion over their work processes on a day-to-day basis will likely result in them feeling energized, enthusiastic and motivated to do a good job for the organisation.

Contrary to expectations and prior research (e.g., Xanthopoulou et al., 2009), and despite having significant within-person bivariate correlations, within-person variation in supervisor support, colleague support and organisational support did not predict within-person variation in engagement in the hierarchical model. These non-significant findings can, in part, be explained by shared variance between each of the support variables and autonomy. It is noteworthy, however, that the influence of with-person organisational support on engagement approached statistical significance, thereby suggesting the potential importance of FIFO organisations demonstrating that they genuinely care about their employees through the provision of appropriate on-the-job and on-site resources (e.g., suitable accommodation, access to telecommunications, etc.).

Consistent with the JD-R health impairment process (Bakker \& Demerouti, 2014), within-person workload and emotional demands were shown to be significant predictors of within-person emotional exhaustion. The results therefore suggest that if FIFO employees perceive their day-level workload is too heavy, do not feel they have enough time to competently complete their daily work, or if they feel they have to suppress their true feelings and portray themselves as being more positive than they actually feel, they will be more likely to experience exhaustion on a daily basis. These findings suggest that organisations wanting to protect the health and wellbeing of their FIFO employees should invest in closely monitoring and managing the quantity and quality of demands experienced by FIFO workers across the course of their FIFO work cycles.

\subsection{Practical Implications}

The substantial within-person variation in job demands, job resources, engagement, and emotional exhaustion across the FIFO work cycle should prompt organisations, managers, supervisors and employees to more consciously acknowledge, monitor and manage these fluctuations. Bakker (2014) argued that organisations need to become more aware of fluctuations in daily work engagement and that "unfortunately, current guidance and policy is completely ignorant of the importance of within-person processes" (p. 234).

Given the direct effects of day-level autonomy on day-level engagement, organisations might usefully look at implementing a range of organisational development and training programs and setting up systems and supports to more effectively embed discretion and 
decision-making authority within the organisational context. Such programs, systems and supports might include establishing senior management's active commitment to more participative work cultures, climates and practices; job re-design; and the redesign of supervisor performance criteria to incorporate the effective management and support of employee participation and autonomy (Albrecht \& Andreeta, 2011). Regular administration of brief 'pulse' surveys may provide useful indicators of the extent to which such processes are being effectively implemented (Lockwood, 2007). Training and development initiatives focused on developing engagement through job crafting interventions (Tims, Bakker \& Derks, 2014) and selfmanagement interventions (Breevaart, Bakker \& Demerouti, 2014) should also be implemented. Job crafting and self-management interventions have been shown to help employees source additional job resources and better manage job demands on a daily basis (Bakker \& Demerouti, 2014). Given job crafting and self-management are 'bottom-up' interventions (Demerouti \& Bakker, 2014), they align particularly well with interventions also aimed to promote autonomy. Additionally, given the small but significant reduction in supervisor support and engagement after every three days of the FIFO work cycle, and given that different workers had different perceptions of their FIFO work experiences, interventions should be targeted by time and by individual employee need. The results also suggest that organisations that employ FIFO work practices should look to actively manage organisational-level supports such as flights, rosters, accommodation, meals, and access to telecommunications.

With respect to the day-level influence of workload and emotional demands on day-level emotional exhaustion, organisations might, for example, look into the possibility of providing opportunities to take scheduled work or 'booster' breaks (Taylor, 2011), and timing such breaks for when FIFO employees are most likely to be experiencing emotional exhaustion. Job crafting and self-management interventions will also help FIFO employees understand and manage workload and emotional demands.

\subsection{Limitations, Future Research, and Conclusion}

Although the present research makes an important contribution to understanding the daylevel predictors of engagement and emotional exhaustion in FIFO work contexts, the study has several limitations. First, as with most diary research, the study used self-report measures, thereby presenting threats associated with common method variance (Podsakoff, MacKenzie, Lee \& Podsakoff, 2003). More objective measures of emotional exhaustion, for example, could usefully be included in future research. Second, despite best efforts to secure participation in the research, a greater number of participants and observations per employee would enable more fine-grain temporal dynamics to be examined. Third, despite a strong theoretical basis and although models of diary data provide benefits over one-shot cross-sectional data, they do not allow for imputing causation. Fourth, the present study measured employee variables mostly using a 3-day frame of reference. Given that studies have also shown that variables such engagement, emotional exhaustion can vary within days (Binnewies \& Woernlein, 2011; Madrid et al., 2014) alternative time frames could usefully be examined. Future research should further examine day-level and intra-day variation to further tease out how temporal dynamics operate over different time frames. Fifth, future research should consider measurements spanning two or more work cycles and examine the role of recovery between FIFO work cycles. This is because researchers have identified that time spent on non-work activities outside of designated work times influences wellbeing and recovery (e.g., Oerlemans \& Bakker, 2014; Sonnentag, 2003).

Future research could also focus on examining the influence of additional job, team and organisational-level resources (e.g. job involvement, psychological safety, job meaningfulness, 
job security), and additional demands (e.g., role ambiguity, job complexity) for their direct and indirect effects on engagement, burnout and performance (Albrecht, Bakker, Gruman, Macey \& Saks, 2015; Bakker, Albrecht \& Leiter, 2010). The moderating influence of such demands and resources could be examined. Importantly, additional qualitative research should be conducted to identify additional FIFO specific demands (e.g., roster patterns) and resources (e.g., internet access) that may more strongly influence wellbeing and performance outcomes (Brough \& Biggs, 2015). Performance outcomes (e.g., task performance, proactive performance, safety behavior, absence) could also be examined.

Despite these limitations, the present study provides several important contributions to the literature. No previous research has examined the day-to-day experiences of FIFO workers. The study highlighted the relevance of job resources and job demands in understanding engagement and burnout in the FIFO working context. It is also the first study to employ Bayesian hierarchical methods to model employee diary data. Furthermore, we demonstrated through confirmatory factor analysis, that the abbreviated measures used in the diary survey had acceptable psychometrics and can potentially be used in future diary research. We hope that this study encourages others to further refine within-person models of employee wellbeing in general and FIFO workers in particular.

\section{References}

Alarcon, G. M. (2011). A meta-analysis of burnout with job demands, resources, and attitudes. Journal of Vocational Behavior, 79, 549-562.

Albrecht, S. L. (2012). The influence of job, team and organizational level resources on employee well-being, engagement, commitment and extra-role performance: Test of a model. International Journal of Manpower, 33 (7), 840-853.

Albrecht, S. L. \& Andreeta, M. (2011). The influence of empowering leadership, empowerment and engagement on affective commitment and turnover intentions in community health service workers: Test of a model. Leadership in Health Services, 24 (3), 228-237.

Albrecht, S. L., Bakker, A. B., Gruman, J. A., Macey, W. H., \& Saks, A. M. (2015). Employee engagement, human resource management practices and competitive advantage: An integrated approach. Journal of Organizational Effectiveness: People and Performance, 2 (1), 7-35.

Albrecht, S. L., \& Su, J. (M). (2012). Job resources and employee engagement in a Chinese context: The mediating roles of job meaningfulness, felt obligation and positive mood. International Journal of Business and Emerging Markets, 4 (4), 277-292.

Anglim, J., Weinberg, M. K., \& Cummins, R. A. (2015). Bayesian hierarchical modeling of the temporal dynamics of subjective well-being: A 10 year longitudinal analysis. Journal of Research in Personality, 59, 1-14.

Australian Federal Government, House of Representatives, Standing Committee on Regional Australia. (2013). Cancer of the bush or salvation for our cities? Fly-in, fly-out and drive-in, drive-out workforce practices in regional Australia. Canberra: The Parliament of the Commonwealth of Australia.

Bakker, A. B. (2014). Daily fluctuations in work engagement: An overview and current directions. European Psychologist, 19 (4), 227-236.

Bakker, A. B., Albrecht, S. L., \& Leiter, M. P. (2011). Key questions regarding work engagement. European Journal of Work and Organizational Psychology, 20, 4-28.

Bakker, A. B., \& Bal, P. M. (2010). Weekly work engagement and performance: A study among starting teachers. Journal of Occupational and Organizational Psychology, 83, 189-206.

Bakker, A. B., \& Demerouti, E. (2014). Job Demands-Resources Theory. In, P. Y. Chen \& C. L. Cooper (Eds.), Work and Wellbeing: Wellbeing: A Complete Reference Guide, (Volume III; pp. 37-64). Chichester, UK: Wiley-Blackwell.

Bakker, A. B., \& Oerlemans, W. (2011). Subjective well-being in organizations. In, K. S. Cameron \& G. M. Spreitzer, G.M. (Eds), The Oxford Handbook of Positive Organizational Scholarship (pp. 178-89). Oxford University Press, New York, NY. 
Barclay, M. A., Harris, J., Everingham, J., Kirsch, P., Arend, S., Shi, S. \& Kim, J. (2013). Factors linked to the wellbeing of fly-in-fly-out (FIFO) workers. Research Report, CSRM and MISHC, Sustainable Minerals Institute, University of Queensland, Brisbane, Australia.

Binnewies, C., \& Woernlein, S. C. (2011). What makes a creative day? A diary study on the interplay between affect, job stressors, and job control. Journal of Organizational Behavior, 32 (4), 589-607.

Breevaart, K., Bakker, A. B., \& Demerouti, E. (2014). Daily self-management and work engagement. Journal of Vocational Behavior, 84, 31-38.

Brough, P., \& Biggs, A. (2015). Job demands x job control interaction effects: Do occupation-specific job demands increase their occurrence? Stress \& Health, 31 (2),138-149.

Christian M. S., Garza A. S., \& Slaughter J. E. (2011). Work engagement: A quantitative review and test of its relations with task and contextual performance. Personnel Psychology, 64, 89-136.

Crawford, E. R., LePine, J. A., \& Rich, B. L. (2010). Linking job demands and resources to employee engagement and burnout: A theoretical extension and meta-analytic test. Journal of Applied Psychology, 95 (5), 834848.

Darr, W., \& Johns, G. (2008). Work strain, health, and absenteeism: A meta-analysis. Journal of Occupational Health Psychology, 13, 293-318.

Demerouti, E., \& Bakker, A. B. (2014). Job crafting. In, M. C. W. Peeters, J. de Jonge \& T. W. Taris, (Eds.), An Introduction to Contemporary Work Psychology, (pp. 414-433). New York, NY: John Wiley \& Sons.

Demerouti, E., Bakker, A. B., Nachreiner, F., \& Schaufeli, W. B. (2001). The job demands- resources model of burnout. Journal of Applied Psychology, 85, 499-512.

Eisenberger R, Huntington, R., Hutchison, S., \& Sowa, D. (1986). Perceived organizational support. Journal of Applied Psychology, 71, 500-507.

Gallegos, D. (2006). Aeroplanes always come back: Fly-in fly-out employment: Managing the parenting transitions. Centre for Social and Community Research, Murdoch University, Australia.

Gelman, A., \& Hill, J. (2007). Data analysis using regression and multilevel/hierarchical models. New York: NY: Cambridge University Press.

Gent, V. M. (2004). The impact of fly-in/fly-out work on well-being and work-life satisfaction (Unpublished honours thesis). Murdoch University, Australia.

Halbesleben, J. R. B. (2010). A meta-analysis of work engagement: Relationships with burnout, demands, resources and consequences. In A. B. Bakker \& M. P. Leiter (Eds.), Work engagement: A handbook of essential theory and research. New York: Psychology Press.

Harter, J. K., Schmidt, F. L., \& Keyes, C. L. (2002). Well-being in the workplace and its relationship with business outcomes: a review of the Gallup studies. In, C. L. Keyes, \& J. Haidt (Eds), Flourishing: The positive person and the good life (pp. 205-224). American Psychological Association, Washington, DC.

Hausser, J. A., Mojzisch, A., Niesel, M., \& Schulz-Hardt, S. (2010). Ten years on: A review of recent research on the Job Demand-Control (-Support) model and psychological well-being. Work \& Stress, 24 (1), 1-35.

Iverson, R., \& Maguire, C. (1999). The relationship between job and life satisfaction: Evidence from a remote mining community. Department of Management Working Paper: The University of Melbourne.

Johnson, J., \& Hall, E. (1988). Job strain, work place social support and cardiovascular disease: A cross-sectional study of a random sample of the working population. American Journal of Public Health, 78, 1336-1342.

Joyce, S. J., Tomlin, S. M., Somerford, P. J., \& Weeramanthri, T. S. (2013). Health behaviours and outcomes associated with fly-in-fly-out and shift workers in Western Australia. Internal Medicine Journal, 43 (4), 440-444.

Karasek, R. A. (1979). Job demands, job decision latitude, and mental strain: Implications for job redesign. Administrative Science Quarterly, 24(2), 285-308.

Karasek, R. A., \& Theorell, T. (1990). Healthy work: Stress, productivity and the reconstruction of working life. New York: Basic Books.

Kühnel, J., Sonnentag, S., \& Bledow, R. (2012). Resources and time pressure as day-level antecedents of work engagement. Journal of Occupational and Organizational Psychology, 85, 181-198.

Kuppens, P., Van Mechelen, I., Nezlek, J. B., Dossche, D., \& Timmermans, T. (2007). Individual differences in core affect variability and their relationship to personality and psychological adjustment. Emotion, 7(2), 262274.

Lockwood, N. R. (2007). Leveraging Employee Engagement for Competitive Advantage: HR's strategic role. Alexandria, VA: SHRM Foundation.

Maas, C. J. M. \& Hox, J. J. (2005). Sufficient sample sizes for multilevel modeling. Methodology, 1 (3), 86-92. 
Madrid, H. P., Patterson, M. G., Birdi, K. S., Leiva, P. I., \& Kausel, E. E. (2014). The role of weekly high-activated positive mood, context, and personality in innovative work behavior: A multilevel and interactional model. Journal of Organizational Behavior, 35, 234-256.

Mäkikangas, A., Kinnunen, S., Rantanen, J., Mauno, S., Tolvanen, A., \& Bakker, A. B. (2014) Association between vigor and exhaustion during the workweek: a person-centered approach to daily assessments. Anxiety, Stress, \& Coping: An International Journal, 27 (5), 555-575.

Muller, R., Carter, A., \& Williamson, A. (2008). Epidemiological diagnosis of occupational fatigue in a Fly-In-Fly-Out operation of the mineral industry. The Annals of Occupational Hygiene, 52 (1), 63-72.

Nahrgang, J. D., Morgeson, F. P., \& Hofmann, D. A. (2011). Safety at work: A meta-analytic investigation of the link between job demands, job resources, burnout, engagement, and safety outcomes. Journal of Applied Psychology, 96, 71-94.

Oerlemans, W. G. M., \& Bakker, A. B. (2014). Burnout and daily recovery: A day reconstruction study. Journal of Occupational Health Psychology, 19 (3), 303-314.

Ouweneel, E., Le Blanc, P. M., Schaufeli, W. B., \& van Wijhe, C. I. (2012). Good morning, good day: A diary study on positive emotions, hope, and work engagement. Human Relations, 65 (9) 1129-1154.

Peetz, D., Murray, D., \& Muurlink, O. (2012). The impact on working arrangements on the physical and psychological health of workers and their partners. Working paper: Griffith University, Brisbane, Australia.

Pini, B., \& Mayes, R. (2012). Gender, emotions and fly-in fly-out work. The Australian Journal of Social Issues, 47 (1), $71-86$

Podsakoff, P. M., MacKenzie, S. B., Lee, J-Y., \& Podsakoff, N. P. (2003). Common method biases in behavioral research: A critical review of the literature and recommended remedies. Journal of Applied Psychology, 88 (5), 879-903.

Rhoades, L. \& Eisenberger, R. (2002). Perceived organizational support: A review of the literature. Journal of Applied Psychology, 87, 698-714.

Rich, B. L., LePine, J. A., Crawford, E. R. (2010). Job engagement: Antecedents and effects on job performance. Academy of Management Journal, 53, 617-635.

Rosseel, Y. (2012). lavaan: An R package for structural equation modeling. Journal of Statistical Software, 48 (2), $1-36$.

Rothmann, S., \& Joubert, J. H. M. (2007). Job demands, job resources, burnout and work engagement of managers at a platinum mine in the North West Province. South African Journal of Business Management, 38 (3), 4961.

Saks, A. M. (2006). Antecedents and consequences of employee engagement. Journal of Managerial Psychology, 27, 600-619.

Schaufeli, W. B., Bakker, A. B., \& Salanova, M. (2006). The measurement of work engagement with a short questionnaire a cross-national study. Educational and Psychological Measurement, 66 (4), 701-716.

Schaufeli, W. B., Leiter, M. P., Maslach, C., \& Jackson, S. E. (1996). Maslach Burnout Inventory - General Survey. In, C. Maslach, S. E. Jackson, \& M. P. Leiter, (Eds.), The Maslach Burnout Inventory-Test manual (3rd ed.). Palo Alto, CA: Consulting Psychologists Press.

Schaufeli, W. B., Salanova, M., González-Romá, V., \& Bakker, A. B. (2002). The measurement of engagement and burnout: A two sample confirmatory factor analytic approach. Journal of Happiness Studies, 3, 71-92.

Schaufeli, W. B., Taris, T. W., \& Van Rhenen, W. (2008). Workaholism, burnout and engagement: Three of a kind or three different kinds of employee well-being? Applied Psychology: An International Review, 57, 173203.

Simbula, S. (2010). Daily fluctuations in teachers' well-being: A diary study using the Job Demands-Resources model. Anxiety, Stress, \& Coping: An International Journal, 23 (5), 563-584.

Sonnentag, S. (2003). Recovery, work engagement, and proactive behavior: A new look at the interface between nonwork and work. Journal of Applied Psychology, 88, 518-528.

Spreitzer, G. M. (1995). Psychological empowerment in the workplace: Dimensions, measurement, and validation. Academy of Management Journal, 38 (5), 1442-1465.

Stansfeld, S., \& Candy, B. (2006). Psychosocial work environment and mental health - a meta-analytic review. Scandinavian Journal of Work, Environment \& Health, 32 (6), 443-462.

Storey, K. (2010). Fly-in/Fly-out: Implications for community sustainability. Sustainability, 2, 1161-1181.

Taylor, W. C. (2011). Booster Breaks: An easy-to-implement workplace policy designed to improve employee health, increase productivity, and lower health care costs. Journal of Workplace Behavioral Health, 26,7084. 
Tetrick, L. E., \& Haimann, C. R. (2014). Occupational demands, environmental resources, personal resources effects on presenteeism and health. In, A. M. Rossi, J. A. Meurs, \& P. L. Perrewé (Eds.), Improving employee health and wellbeing (pp. 25-34). USA: Information Age Publishing.

Tims, M., Bakker, A. B., \& Derks, D. (2014). Daily job crafting and the self-efficacy-performance relationship. Journal of Managerial Psychology, 29 (5), 490-507.

Torkington, A.M., Larkins, S., \& Gupta, T.S. (2011). The psychosocial impacts of fly-in-fly-out and drive-in-driveout mining on mining employees: A qualitative study. The Australian Journal of Rural Health, 19 (3), 135141.

van Gelderen, B. R., Bakker, A. B., Konijn, E. A., \& Binneweis, C. (2014). Daily deliberative dissonance acting among police officers. Journal of Managerial Psychology, 29 (7), 884-900.

Viswesvaran, C., Sanchez, J. I., \& Fisher, J. (1999) The role of social support in the process of work stress: A metaanalysis. Journal of Vocational Behavior, 54, 314-334.

Vojnovic, P. \& Bahn, S. (2015). Depression, anxiety amd stress symptomsamong Fly-In Fly-Out Australian industry workers. Journal of Health, Safety and Environment, 31 (3), 207-223.

Vojnovic, P., Michelson, G., Jackson, D., \& Bahn, S. (2014). Adjustment, well-being and help-seeking among Australian FIFO Mining employees. Australian Bulletin of Labour, 40 (2), 242-261.

Western Australian Government (2015). The impact of FIFO work practices on mental health: Final report. Perth, Western Australia: The Parliament of Western Australia.

Xanthopoulou, D., Bakker, A. B., Demerouti, E., Schaufeli, W. B. (2007). The role of personal resources in the Job Demands-Resources Model. International Journal of Stress Management, 14 (2), 121-141.

Xanthopoulou, D., Bakker, A. B., Demerouti, E., Schaufeli, W. B. (2009). Work engagement and financial returns: A diary study on the role of job and personal resources. Journal of Occupational and Organizational Psychology, 82, 183-200.

Xanthopoulou, D., Bakker, A. B., Heuven, E., Demerouti, E., Schaufeli, W. B. (2008). Working in the sky: A diary study among flight attendants. Journal of Occupational Health Psychology, 13 (4), 345-356.

Zapf, D., Seifert, C., Schmutte, B., Mertini, H., \& Holz, M. (2001). Emotion work and job stressors and their effects on burnout. Psychology \& Health, 16 (5), 527-545. 